\title{
PENYULUHAN DENGAN MEDIA AUDIOVISUAL MEMENGARUHI TINGKAT PENGETAHUAN IBU TENTANG KEBUTUHAN DASAR IBU HAMIL
}

\author{
Sitti Hadijah ${ }^{\bowtie}$, Hidayati, Indriani, Wirawati Amin \\ Jurusan Kebidanan Poltekkes Kemenkes Makassar
}

\section{ARTICLE INFO \\ Article history}

Submitted : 2021-07-07

Revised : 2021-08-09

Accepted : 2021-08-16

\section{Keywords:}

Counseling

Audiovisual media

Level of knowledge

Basic needs

Pregnant women

\section{Kata Kunci:}

\section{Penyuluhan}

Media audiovisual

Tingkat pengetahuan

Kebutuhan dasar

Ibu hamil

\begin{abstract}
Efforts to accelerate the reduction of the Maternal Mortality Rate (MMR) can be carried out by ensuring that every mother is able to access quality maternal health services. Audiovisual media is one of the extension media that stimulates the senses of sight and hearing so as to increase mother's knowledge about the basic needs of pregnant women. This study aims to determine the effect of counseling with audiovisual media on the level of knowledge of mothers about the basic needs of pregnant women. The type of research used is a quasi-experimental research design non equivalent control group design. The sampling technique in this study used a consecutive sampling technique, as many as 32 respondents in the experimental group and 32 respondents in the control group. The statistical test used was the Wilcoxon test and the Mann Withney U-Test. From the results of the Wicoxon test in the two treatment groups, it was found that the $p$ value (Asymp. Sig 2-tailed) was $0.000<0.05$ so it could be concluded that there were significant differences in the extension group with audiovisual media and the extension group with leaflet media. The results of the analysis of the Mann Withney U-Test showed the largest $\mathrm{p}$-value of $0.003<0.05$ so it can be concluded that audiovisual counseling is more effectively used to increase mother's knowledge about the basic needs of pregnant women compared to leaflet media.

Upaya percepatan penurunan Angka Kematian Ibu (AKI) dapat dilakukan dengan menjamin agar setiap ibu mampu mengakses pelayanan kesehatan ibu yang berkualitas. Media audiovisual merupakan salah satu media penyuluhan yang memberi stimulasi terhadap indra penglihatan dan pendengaran sehingga mampu meningkatkan pengetahuan ibu tentang kebutuhan dasar ibu hamil. Penelitian ini bertujuan untuk mengetahui pengaruh penyuluhan dengan media audiovisual terhadap tingkat pengetahuan ibu tentang kebutuhan dasar ibu hamil. Jenis penelitian yang digunakan adalah quasi eksperimental dengan desain penelitian non equivalent control group design. Teknik pengambilan sampling dalam penelitian ini menggunakan teknik consecutive sampling yaitu sebanyak 32 responden pada kelompok eksperimen dan 32 responden pada kelompok kontrol. Uji statistik yang digunakan adalah uji Wilcoxon dan uji Mann Withney U-Test. Dari hasil uji Wicoxon pada kedua kelompok perlakuan didapatkan bahwa nilai $\mathrm{p}$ value (Asymp. Sig 2-tailed) sebesar $0,000<0,05$ sehingga dapat disimpulkan bahwa terdapat perbedaan yang signifikan pada kelompok penyuluhan dengan media audiovisual maupun kelompok penyuluhan dengan media leaflet. Hasil analisa dari uji Mann Withney U-Test didapatkan hasil terbesar p-value $0,003<0,05$ sehingga dapat disimpulkan bahwa penyuluhan dengan media audiovisual lebih efektif digunakan untuk meningkatkan pengetahuan ibu tentang kebutuhan dasar ibu hamil dibandingkan dengan media leaflet.
\end{abstract}

$\triangle$ Corresponding Author:

Sitti Hadijah

Jurusan Kebidanan Poltekkes Kemenkes Makassar

Telp. 081355878497

Email: sitti.hadijah211@poltekkes-mks.ac.id

\section{PENDAHULUAN}

Angka Kematian Ibu (AKI) merupakan salah satu indikator untuk melihat keberhasilan upaya kesehatan ibu. AKI adalah rasio kematian ibu selama masa kehamilan, persalinan dan nifas yang disebabkan oleh kehamilan, persalinan, dan nifas atau pengelolaannya tetapi bukan karena sebabsebab lain seperti kecelakaan atau terjatuh di setiap 100.000 kelahiran hidup. Selain untuk menilai program kesehatan ibu, indikator ini juga mampu menilai derajat kesehatan masyarakat, karena sensitifitasnya terhadap perbaikan pelayanan kesehatan, baik dari sisi 
aksesibilitas maupun kualitas. Secara umum terjadi penurunan kematian ibu selama periode 1991 - 2015 dari 390 menjadi 305 per 100.000 kelahiran hidup. Upaya percepatan penurunan AKI dapat dilakukan dengan menjamin agar setiap ibu mampu mengakses pelayanan kesehatan ibu yang berkualitas (Kemenkes RI, 2018).

Selama masa kehamilan terjadi banyak perubahan baik secara anatomi, fisiologi, biologi dan mekanika tubuh pada ibu hamil. Perubahan yang terjadi ini terutama pada ibu untuk pertama kali hamil, membuat ibu menjadi rentan baik fisik maupun mental (Abedi et al., 2012). Asuhan kehamilan sangat berkaitan dengan fungsi reproduksi wanita sehingga upaya tersebut sangat dipengaruhi oleh perilaku ibu hamil sendiri. Pentingnya dilakukan asuhan kehamilan yang baik agar ibu dalam menjalani kehamilannya terjaga dengan baik (Stephanie et al., 2016).

Informasi selama kehamilan yang didapatkan oleh ibu hamil untuk meningkatkan pengetahuan seputar kehamilan didapatkan melalui berbagai sumber seperti media sosial, majalah, website, leaflet kehamilan atau informasi langsung dari keluarga dan teman. Berbagai sumber yang ibu hamil peroleh kemungkinan akan menyebabkan kebingungan dalam memenuhi kebutuhan dasar selama kehamilan, aspek tersebut seperti nutrisi, pola istirahat/tidur, aktivitas, bekerja, berpergian, olahraga dan hubungan seksual, personal hygiene, imunisasi, senam hamil. Wanita hamil biasanya akan menemui tenaga kesehatan/bidan untuk mendapatkan arahan yang baik untuk menjalani kehamilannya, bidan pun akan memberikan saran-saran untuk kehamilannya (Fox, 2018).

Seorang ibu hamil yang memiliki pengetahuan yang baik maka ia juga akan memiliki sikap dan perilaku yang baik pula dalam menjalani kehamilannya. Pengetahuan dipengaruhi oleh beberapa faktor diantaranya usia, pendidikan, pekerjaan, paritas, dukungan keluarga dan ekonomi (Gamelia et al., 2013).

Pemenuhan kebutuhan dasar selama kehamilan, memiliki peranan penting bagi kesehatan ibu dan bayinya. Hal ini tidak lepas dari motivasi ibu sendiri untuk dapat memenuhi kebutuhan dasarnya, namun dukungan dari pihak keluarga turut membantu terpenuhinya kebutuhan dasar dalam kehamilan. Penelitian yang dilakukan (Kocher et al., 2018) diperoleh hasil bahwa wanita hamil memiliki motivasi secara eksternal lebih tinggi untuk melakukan perilaku hidup sehat selama kehamilannya terutama manfaat yang dirasakan untuk kesehatan bayinya. Selama kehamilan wanita hamil mendapatkan perhatian, perlindungan dan dukungan dari keluarga untuk menjaga kesehatan dirinya dan bayinya.

Hasil penelitian yang dilakukan (Indrayati \& Hikmah, 2017) memperoleh hasil bahwa ibu hamil yang memiliki pengetahuan yang baik, akan memiliki sikap dan perilaku yang baik tentang pemeliharaan kesehatan diri selama kehamilan sampai masa nifasnya. Hubungan yang diperoleh adalah hubungan yang positif. Hal ini berarti upaya yang dilakukan oleh tenaga kesehatan dalam memberdayaan ibu hamil agar dapat menjaga kesehatan diri selama kehamilan agar dapat mengubah sikap dan perilaku penting untuk dilakukan secara berkelanjutan. Penelitian ini memperoleh data bahwa pengetahuan ibu berpengaruh pada pelaksanaan pemenuhan kebutuhan dasar selama kehamilan. Pentingnya peran dari tenaga kesehatan dalam hal ini adalah bidan untuk memberikan pengetahuan pada ibu hamil, sehingga ibu hamil dapat mengetahui informasi seputar kehamilan yang akan berdampak positif ke ibu hamil.

Hasil penelitian yang dilakukan (Ersila et al., 2020) tentang analisis faktor yang berhubungan dengan pelaksanaan pemenuhan kebutuhan dasar pada Ibu Hamil di Kabupaten Pekalongan memperoleh hasil bahwa ibu hamil memiliki pengetahuan yang baik sejumlah 64 $(58 \%)$. Hal ini menunjukkan bahwa informasi yang telah diterima ibu baik secara formal atau non formal memberikan dampak terhadap pengetahuan ibu hamil mengenai kebutuhan dasar selama kehamilan. Pengetahuan pada ibu hamil menentukan tingkat kesehatan ibu hamil. Ibu hamil yang memiliki pengetahuan yang baik mengenai kebutuhan dasar selama kehamilan, maka akan memiliki pelaksanaan yang baik pula.

Puskesmas Towea merupakan puskesmas di bawah naungan Dinas Kesehatan Kabupaten Muna Provinsi Sulawesi Tenggara. Data dari puskesmas Towea menyebutkan bahwa jumlah ibu hamil pada tahun 2020 sebesar 100 orang. Jumlah ibu hamil yang melakukan kunjungan rata-rata sekitar $70 \mathrm{ibu}$ hamil sejak bulan Januari hingga bulan Oktober. Berdasarkan wawancara dengan 
bidan, pemberian informasi kepada ibu hamil mengenai pemenuhan kebutuhan dasar pada ibu hamil masih belum maksimal, karena keterbatasan waktu dan jumlah ibu yang periksa banyak, sehingga untuk meningkatkan pengetahuan ibu hamil mengenai informasi kehamilan, bidan lebih banyak menganjurkan ibu untuk membaca di buku Kesehatan Ibu dan Anak.

Penyuluhan dengan media mampu membangkitkan dan membawa ibu hamil ke dalam suasana rasa senang dan gembira, dimana ada keterlibatan emosional dan mental (Juliantara, 2009). Efektivitas penggunaan media penyuluhan sangat ditentukan oleh banyaknya indra penerimaan yang terlibat. Semakin banyak indra yang digunakan, penyampaian pesan penyuluhan semakin mudah dimengerti. Media audiovisual berupa video sangat efektif dalam penyerapan materi karena $82 \%$ melibatkan panca indra penglihatan dan $11 \%$ panca indra pendengaran dibandingkan media lain. Berdasarkan uraian diatas, peneliti tertarik untuk melakukan penelitian dengan judul pengaruh penyuluhan dengan media audiovisual terhadap tingkat pengetahuan ibu tentang kebutuhan dasar ibu hamil di Puskesmas Towea Kabupaten Muna.

\section{METODE PENELITIAN}

\section{Jenis Penelitian}

Jenis penelitian ini adalah penelitian intervensi dengan menggunakan desain penelitian quasi eksperimen non equivalent control group design.

\section{Lokasi dan Waktu Penelitian}

Penelitian dilaksanakan di Kecamatan Towea, wilayah kerja Puskesmas Towea, Kabupaten Muna pada Bulan Februari - Mei 2021.

\section{Populasi dan Sampel}

Populasi dalam penelitian ini adalah seluruh ibu hamil yang memeriksakan kehamilannya di Puskesmas Towea Kabupaten Muna yaitu sebanyak 100 ibu hamil. Sampel dalam penelitian ini adalah seluruh ibu hamil yang memeriksakan kehamilannya di Puskesmas Towea Kabupaten Muna yaitu sebanyak 64 ibu hamil.

Teknik pengambilan sampel yang dilakukan dengan cara Consecutive Sampling yang memenuhi kriteria inklusi yaitu seluruh ibu hamil yang memeriksakan kehamilannya di Puskesmas Towea, bersedia menjadi responden, mengisi informed consent, dan mengikuti penyuluhan serta menjawab seluruh pertanyaan pada kuesioner tentang kebutuhan dasar ibu hamil pada pretest dan posttest.

\section{Pengumpulan Data}

Pengambilan data dilakukan dengan pengisian 10 pertanyaan pada kuesioner tentang kebutuhan dasar ibu hamil dengan menggunakan skala Guttman. Menurut (Arikunto, 2010), kategori tingkat pengetahuan seseorang dapat dibagi menjadi tiga tingkatan yang didasarkan pada nilai persentase yaitu tingkat pengetahuan kategori baik jika nilainya $\geq 76-100 \%$, tingkat pengetahuan kategori cukup jika nilainya $60-75 \%$ dan tingkat pengetahuan kategori kurang jika nilainya < $60 \%$.

\section{Pengolahan dan Analisis Data}

Pengolahan data dilakukan dengn menggunakan komputer program SPSS (Statistical Package For Social Science). Proses yang dilakukan dimulai dengan tahapan editing, coding, entry data, cleaning data, dan penyajian data dalam bentuk tabel distribusi frekuensi.

Analisis data yang digunakan dalam penelitian ini adalah analisis bivariat yang digunakan untuk mencari hubungan variabel independen dan variabel dependen dengan menggunakan tabel. Adapun uji yang digunakan adalah uji Wilcoxon dan uji Mann Withney dengan nilai $\mathrm{p}<0,05$.

\section{HASIL PENELITIAN}

Selama penelitian, didapatkan 64 ibu hamil yang bersedia menjadi responden penelitian. Karakteristik subjek Karakteristik subjek penelitian dapat dilihat pada tabel 1 .

\section{Uji Normalitas}

Uji normalitas dilakukan dengan menggunakan uji One Sample Kolmogorov-Smirnov dengan software komputer sebagai berikut:

\section{Kelompok Penyuluhan dengan Media Audiovisual}

Hasil perhitungan uji normalitas pengetahuan sebelum penyuluhan dengan media audiovisual adalah $0,000<0,05$. Hasil perhitungan uji normalitas pengetahuan sesudah penyuluhan dengan media audiovisual adalah $0,000<0,05$. Dari $p$-value ini dapat diketahui bahwa data tidak berdistribusi normal, sehingga analisis peningkatan pengetahuan pada 
kelompok penyuluhan dengan media audiovisual dilakukan dengan Wilcoxon.

\section{Tabel 1. Karakteristik Subjek Penelitian}

\begin{tabular}{lcccc}
\hline \multirow{2}{*}{ Variabel } & $\begin{array}{c}\text { Kelompok } \\
\text { Eksperimen }\end{array}$ & \multicolumn{2}{c}{$\begin{array}{c}\text { Kelompok } \\
\text { Kontrol }\end{array}$} \\
\cline { 2 - 5 } & $\mathbf{n}$ & $\mathbf{\%}$ & $\mathbf{n}$ & $\mathbf{\%}$ \\
\hline Usia & & & & \\
$<20$ tahun & 5 & 15,6 & 4 & 12,5 \\
$20-35$ tahun & 23 & 71,9 & 25 & 78,1 \\
$>35$ tahun & 4 & 12,5 & 3 & 9,4 \\
Pendidikan & & & & \\
SD & 13 & 40,6 & 15 & 46,9 \\
SMP & 12 & 37,5 & 14 & 43,8 \\
SMA & 5 & 15,6 & 3 & 9,4 \\
S1 & 2 & 6,3 & 0 & 0 \\
\hline Jumlah & $\mathbf{3 2}$ & $\mathbf{1 0 0}$ & $\mathbf{3 2}$ & $\mathbf{1 0 0}$ \\
\hline Sumber: Data Primer Tahn 2021 & &
\end{tabular}

Sumber: Data Primer Tahun 2021

Kelompok Penyuluhan dengan Media Leaflet Hasil perhitungan uji normalitas pengetahuan sebelum penyuluhan dengan media leaflet adalah $0,000<0,05$. Hasil perhitungan uji normalitas pengetahuan sesudah penyuluhan dengan media leaflet adalah $0,000<0,05$. Dari p-value ini dapat diketahui bahwa data tidak berdistribusi normal, sehingga analisis peningkatan pengetahuan pada kelompok penyuluhan dengan media leaflet dilakukan dengan uji Wilcoxon.

Perbandingan Peningkatan Pengetahuan pada Kelompok Penyuluhan dengan Media Audiovisual dan Kelompok Penyuluhan dengan Media Leaflet

Hasil perhitungan uji normalitas peningkatan pengetahuan pada kelompok penyuluhan dengan media audiovisual adalah $0,000<0,05$. Hasil perhitungan uji normalitas peningkatan pengetahuan pada kelompok penyuluhan dengan media leaflet adalah $0,000<0,05$. Dari p-value ini dapat diketahui bahwa data tidak berdistribusi normal, sehingga analisis perbandingan peningkatan pengetahuan pada kelompok penyuluhan dengan media audiovisual dan kelompok penyuluhan dengan media leaflet dilakukan dengan uji Mann Whitney.

Tingkat Pengetahuan pada Kelompok Penyuluhan dengan Media Audiovisual dan Media Leaflet

Rata-rata pengetahuan pada kelompok penyuluhan dengan media audiovisual sebelum diberi penyuluhan adalah 6,13 dan sesudah diberi penyuluhan adalah 9,88. Perbedaan peningkatan pengetahuan pada kelompok penyuluhan dengan media audiovisual adalah 3,75. Rata-rata pengetahuan pada kelompok penyuluhan dengan media leaflet sebelum diberi penyuluhan adalah 5,72 dan sesudah diberi penyuluhan adalah 9,22. Perbedaan peningkatan pengetahuan pada kelompok penyuluhan dengan media leaflet adalah 3,50. Data ini kemudian dianalisis menggunakan uji Wilcoxon dengan software komputer dan menghasilkan $\mathrm{p}$-value sebesar 0,000 . P-value < 0,05 menunjukkan bahwa ada peningkatan pengetahuan yang bermakna pada kelompok penyuluhan dengan media audiovisual maupun media leaflet.

Pengetahuan respon den digolongkan berdasarkan skor hasil post-test. Tingkat pengetahuan responden dalam penelitian ini dikatakan baik bila skor $76-100 \%$, pengetahuan cukup bila skor $60-75 \%$, dan pengetahuan kurang bila skor $<60 \%$.

Tabel 2. Perbandingan Pengetahuan Sebelum dan Sesudah Penyuluhan dengan Media Audiovisual dan Media Leaflet

\begin{tabular}{|c|c|c|c|c|c|}
\hline \multirow[t]{2}{*}{ Pengetahuan } & \multirow[t]{2}{*}{$\mathbf{N}$} & \multicolumn{2}{|c|}{$\begin{array}{c}\text { Kelompok } \\
\text { Eksperimen } \\
\text { (Audiovisual) } \\
\end{array}$} & \multicolumn{2}{|c|}{$\begin{array}{c}\text { Kelompok } \\
\text { Kontrol } \\
\text { (Leaflet) } \\
\end{array}$} \\
\hline & & Mean & $\begin{array}{c}\text { Standar } \\
\text { Deviasi }\end{array}$ & Mean & $\begin{array}{c}\text { Standar } \\
\text { Deviasi }\end{array}$ \\
\hline $\begin{array}{l}\text { Sebelum } \\
\text { Penyuluhan }\end{array}$ & 32 & 6,13 & 1,157 & 5,72 & 1,023 \\
\hline $\begin{array}{l}\text { Sesudah } \\
\text { Penyuluhan }\end{array}$ & 32 & 9,88 & 0,336 & 9,22 & 1,157 \\
\hline
\end{tabular}

Perbandingan Peningkatan Pengetahuan Kelompok Penyuluhan dengan Media Audiovisual dengan Media Leaflet

Kelompok penyuluhan dengan media audiovisual dan kelompok penyuluhan dengan media leaflet keduanya mempunyai peningkatan pengetahuan sebelum dan sesudah penyuluhan. Pengaruh peningkatan pengetahaun pada kelompok penyuluhan dengan media audiovisual lebih besar yaitu sebesar 3,75 dibandingkan kelompok penyuluhan dengan media leaflet yaitu sebesar 3,50 .

Data kemudian dianalisis dengan menggunakan uji Mann Withney dengan software komputer dan menghasilkan p-value sebesar $0,003<0,05$. Nilai ini menunjukkan 
bahwa kelompok penyuluhan dengan media audiovisual mengalami peningkatan lebih tinggi dibandingkan kelompok penyuluhan dengan media leaflet.

Tabel 3. Perbandingan Peningkatan Pengetahuan Kelompok Penyuluhan dengan Media Audiovisual dengan Media Leaflet

\begin{tabular}{llcc}
\hline \multicolumn{1}{c}{ Kelompok } & N & Mean & $\boldsymbol{P}$ \\
\hline $\begin{array}{l}\text { Eksperimen } \\
\text { (Audiovisual) }\end{array}$ & 32 & 3,75 & \\
$\begin{array}{l}\text { Kontrol } \\
\text { (Leaflet) }\end{array}$ & 32 & 3,50 & 0,003 \\
\hline Sumber: Data Primer Tahun 202l & & \\
\hline
\end{tabular}

\section{PEMBAHASAN}

Dalam melakukan intervensi pada pengetahuan akan melalui proses kegiatan belajar. Di dalam kegiatan belajar terdapat tiga persoalan pokok yaitu masukan (input), proses, dan keluaran (output). Persoalan masukan (input) menyangkut subjek atau sasaran belajar itu sendiri dengan berbagai latar belakangnya. Persoalan proses yaitu mekanisme atau proses terjadinya perubahan kemampuan pada diri subjek belajar. Persoalan keluaran (output) yaitu hasil belajar itu sendiri (Notoatmodjo, $\underline{2014)}$. Intervensi pada penelitian ini berfokus pada proses yaitu dilakukan intervensi penyuluhan dengan media audiovisual untuk meningkatkan keluaran yaitu pengetahuan ibu tentang kebutuhan dasar ibu hamil.

Seluruh responden memiliki presentase tingkat pendidikan sekolah dasar (SD) dan berusia $20-35$ tahun. Pada kelompok eksperimen dan kelompok kontrol mayoritas responden memiliki tingkat pengetahuan baik setelah mengikuti penyuluhuan tentang kebutuhan dasar ibu hamil.

Kelompok penyuluhan dengan media audiovisual dan kelompok penyuluhan dengan media leaflet sama-sama mengalami peningkatan pengetahuan pada tiga hari setelah diberi penyuluhan. Kelompok penyuluhan dengan media audiovisual mengalami peningkatan yang lebih besar yaitu, 3,75 dibandingkan kelompok penyuluhan dengan media leaflet yaitu 3,50. Dari hasil uji Wilcoxon dengan software komputer didapatkan nilai $\mathrm{p}$ value $0,000<0,05$. Dari nilai tersebut dapat disimpulkan bahwa terdapat peningkatan pengetahuan yang bermakna pada penyuluhan dengan media audiovisual maupun penyuluhan dengan media leaflet.

Dari hasil uji Mann Withney dengan software komputer didapatkan nilai p-value $0,003<0,05$. Dari nilai tersebut dapat disimpulkan bahwa terdapat perbedaan peningkatan pengetahuan yang bermakna antara kelompok penyuluhan dengan media audiovisual dan kelompok penyuluhan dengan media leaflet. Pemberian penyuluhan dengan menggunakan media audiovisual berpengaruh lebih besar terhadap peningkatan pengetahuan dibandingkan pada kelompok penyuluhan dengan media leaflet.

Pemberian penyuluhan dengan menggunakan media audiovisual merupakan kegiatan pendidikan yang dilakukan dengan cara menyebarkan pesan, menanamkan keyakinan, sehingga responden tidak saja sadar, tahu, dan mengerti, tetapi juga mau dan bisa melakukan suatu anjuran yang disampaikan dengan menggunakan media audiovisual (Azwar, 2013). Efektifitas penggunaan media penyuluhan sangat ditentukan oleh banyaknya indera penerimaan yang terlibat. Semakin banyak indera yang digunakan, penyampaian pesan penyuluhan semakin mudah dimengerti.

Dari penelitian ini, diketahui bahwa penyuluhan dengan media audiovisual mampu meningkatkan pengetahuan ibu hamil tentang pemenuhan kebutuhan dasar selama masa kehamilan sehingga dapat meningkatkan kesehatan pada ibu dan bayi. Penelitian ini sejalan dengan penelitian yang dilakukan (Ersila et al., 2020) tentang analisis faktor yang berhubungan dengan pelaksanaan pemenuhan kebutuhan dasar pada Ibu Hamil di Kabupaten Pekalongan memperoleh hasil bahwa ibu hamil memiliki pengetahuan yang baik sejumlah 64 (58\%). Hal ini menunjukkan bahwa informasi yang telah diterima ibu baik secara formal atau non formal memberikan dampak terhadap pengetahuan ibu hamil mengenai kebutuhan dasar selama kehamilan. Hal ini sejalan juga dengan penelitian yang dilakukan (Indrayati \& Hikmah, 2017) memperoleh hasil bahwa ibu hamil yang memiliki pengetahuan yang baik, akan memiliki sikap dan perilaku yang baik tentang pemeliharaan kesehatan diri selama kehamilan sampai masa nifasnya.

Media audiovisual merupakan media yang menggabungkan indera penglihatan dan pendengaran dalam proses daya serap pembelajaran, sedangkan media leaflet hanya mengandalkan indera penglihatan sehingga 
daya serap dalam pembelajaran menjadi kurang maksimal. Hal ini sesuai dengan teori Benyamin $L$ Bloom yang menyatakan bahwa pengetahuan merupakan hasil dari tahu dan ini terjadi setelah orang melakukan pengindraan terhadap suatu objek tertentu, yang sangat penting dalam membentuk tindakan seseorang (Notoatmodjo, 2014).

Dari hasil penelitian ini, diketahui bahwa ada pengaruh penyuluhan dengan media audiovisual terhadap tingkat pengetahan ibu tentang kebutuhan dasar ibu hamil. Hal ini dapat dilihat dari adanya peningkatan pengetahuan pada kelompok penyuluhan menggunakan media audiovisual yang lebih tinggi dibandingkan dengan kelompok penyuluhan menggunakan media leaflet karena lebih banyak indra yang terlibat dalam penerimaan pesan melalui media audiovisual dibandingkan media leaflet.

\section{KESIMPULAN DAN SARAN}

Berdasarkan hasil penelitian dapat diambil sebuah kesimpulan bahwa terdapat pengaruh penyuluhan dengan media audiovisual terhadap tingkat pengetahuan ibu tentang kebutuhan dasar ibu hamil di Puskesmas Towea Kabupaten Muna. Pemberian penyuluhan dengan menggunakan media audiovisual dapat digunakan sebagai alternatif untuk meningkatkan pengetahuan dalam melaksanakan promosi kesehatan.

Peneliti selanjutnya diharapkan dapat melakukan pengembangan penelitian dengan membandingkan efektivitas media audiovisual dengan media lain seperti media hiburan berupa iklan. Berdasarkan hal tersebut diharapkan dapat ditemukan media-media penyuluhan yang tepat guna.

\section{DAFTAR PUSTAKA}

Abedi, G., Babamiri, F., \& Rostami, F. (2012). Pregnant women life quality concept \& phenomenology. International Journal of Collaborative Research on Internal Medicine and Public Health, 4(7), 14121418.

Arikunto, S. (2010). Prosedur Penelitian Suatu Pendekatan Praktik. Rineka Cipta.
Azwar, S. (2013). Sikap Manusia, Teori, dan Pengukurannya. Pustaka Pelajar.

Ersila, W., Zuhana, N., \& Prafitri, L. D. (2020). Analisis Faktor yang Berhubungan dengan Pelaksanaan Pemenuhan Kebutuhan Dasar pada Ibu Hamil di Kabupaten Pekalongan. Jurnal Ilmiah Kesehatan Keperawatan, 16(1), 68. https://doi.org/10.26753/jikk.v16i1.444

Fox, N. S. (2018). Dos and Don'ts in Pregnancy: Truths and Myths. Obstetrics \& Gynecology, 131(4), 713-721.

Gamelia, E., Sistiarani, C., Masfiah, S., \& Fakultas, M. (2013). Determinant of mother's prenatal care behaviour. $J$ Kesehat Masy Nas, 8(3), 109-114.

Indrayati, A., \& Hikmah, N. I. (2017). Pemberdayaan Ibu Hamil Melalui Perawatan Diri Sebagai Upaya Pengurangan Risiko Kematian Maternal Di Kecamatan Tretep Kabupaten Temanggung. Prosiding Seminar Nasional Geografi UMS 2017 Pengelolaan Sumberdaya Wilayah Berkelanjutan, 728-739. https:// publikasiilmiah.ums.ac.id/xmlui/bitstrea m/handle/11617/9190/semnasgeo2017_6 6.pdf? sequence $=1 \&$ is Allowed $=\mathrm{y}$.

Juliantara. (2009). Teknoloi Informatika. Citra Aditya.

Kemenkes RI. (2018). Profil Kesehatan Indonesia 2018 (R. Kurniawan, Yudianto, B. Hardhana, \& T. Siswanti (eds.)). Kementerian Kesehatan RI. 2019.

Kocher, E. L., Lamb, J. M. S., McGarvey, S. T., Muasau-Howard, B. T., \& Hawley, N. L. (2018). Conceptions of pregnancy health and motivations for healthful behavior change among women in American Samoa. Women and Birth, 31(1), e32e41.

Notoatmodjo, S. (2014). Ilmu Perilaku Kesehatan. Rineka Cipta.

Stephanie, O., Michael, O., \& Karolina, S. (2016). Normal Pregnancy: A Clinical Review. Academic Journal of Pediatrics \& Neonatology, 1(1), 15-18. https://doi.org/10.19080/ajpn.2016.01.55 5554. 